\title{
TEMPORARY AND PERMANENT MYXEDEMA FOLLOWING TREATED AND UNTREATED THYROTOXICOSIS ${ }^{1}$
}

By WILLARD OWEN THOMPSON ${ }^{2}$ AND PHEBE K. THOMPSON ${ }^{3}$

(From the Thyroid Clinic and Metabolism Laboratory of the Massachusetts General Hospital)

(Received for publication August 20, 1928)

Although myxedema following treatment for toxic goiter has been reported frequently before, we wish to call attention to certain of its aspects which we regard as particularly worthy of emphasis, viz., (a) the existence of two types-temporary and permanent, $(b)$ the rarity of the permanent type, $(c)$ its late onset after x-ray therapy, $(d)$ its occurrence following untreated toxic goiter. The permanent type will be considered first.

\section{PERMANENT MYXEDEMA FOLLOWING TREATED THYROTOXICOSIS}

\section{A. Rarity}

In the pioneer days of goiter surgery, when thyroidectomies were usually complete, post-operative myxedema was very common, occurring in at least 33 per cent of the cases thus treated. ${ }^{4}$ It was noted, however, that when thyroidectomies had been partial the incidence was only 1 per cent (1). The latter method soon supplanted the former, with the result that permanent myxedema became, and in general has remained, a practically negligible sequel to the surgical treatment of goiter.

Judd (2), in observations on the surgery of the thyroid states "In our series of cases we have not observed a permanent post-operative

1 This study was aided by a grant from the Proctor Fund of the Harvard Medical School, for the Study of Chronic Diseases.

2 Fellow of the National Research Council. Research Fellow in Medicine at the Harvard Medical School and at the Massachusetts General Hospital.

3 Research Fellow in Medicine at the Massachusetts General Hospital.

- This refers to cases of "simple" goiter. 
myxedema, and in many instances a very large part of the thyroid has been removed." Jordan (3) states that post-operative myxedema occurred in 0.9 per cent of a "primary hyperthyroidism" series of 533 cases treated by subtotal thyroidectomy and in 0.9 per cent of a "secondary hyperthyroidism" series of 320 cases treated by various types of partial thyroidectomy. Smith, Clute and Strieder (4), however, in a more recent (1928) publication from the same clinic, report that in 100 patients followed for 1 year or more after subtotal thyroidectomy, their incidence of post-operative myxedema has increased to 15 per cent. This they attribute to the recent practice of removing a larger portion of thyroid gland than formerly, and also to the postoperative use of iodine. Elliott (5), in a study of the results of thyroidectomy for toxic goiter, gives figures showing that of 74 cases undergoing a maximal subtotal thyroidectomy, 3 showed evidence of post-operative myxedema. Jordan, Smith, Clute and Strieder and Elliott do not state whether the myxedema was temporary or permanent.

The statistics of the Thyroid Clinic of the Massachusetts General Hospital indicate that following either $\mathrm{x}$-ray treatment or subtotal thyroidectomy, permanent myxedema is a rare occurrence. A subtotal thyroidectomy in this hospital involves the removal of at least three-fourths and usually five-sixths to seven-eights of the gland. Iodine has been used for several months post-operatively in many of the cases since the year 1924. The type of $x$-ray therapy used in the majority of instances was the exposure of both thyroid and thymus glands to about two-thirds the erythema dose. Treatments were usually given 3 to 4 weeks apart. During the period 1915-1926 inclusive, 465 cases of toxic goiter (for the most part exophthalmic goiter) were treated as follows:

130 by $\mathrm{x}$-ray only.

213 by subtotal thyroidectomy only, in one or more stages.

122 by more limited operations, often with $\mathrm{x}$-ray in addition, or else by subtotal thyroidectomy and $\mathrm{x}$-ray combined.

Only 8 cases of myxedema which was apparently permanent were observed among the above 465 cases, i.e., about 2 per cent. Five of these occurred after $x$-ray treatment, 1 after subtotal thyroidectomy, 
and 2 after a subtotal combined with $x$-ray. Thus, after $x$-ray alone, the incidence was about 4 per cent, and after subtotal thyroidectomy alone, about 0.5 per cent. Approximately half the patients were followed from 1 to 11 years after treatment. Even allowing for the deficiency in follow-up work and for the comparatively small series, the incidence of permanent myxedema is distinctly low. A temporary edema suggesting myxedema (6) is a common sequel to treatment for toxic goiter, as also is permanent low metabolism without myxedema (7). It should be kept in mind that we refer to neither of these when stressing the rarity of permanent myxedema.

\section{B. Clinical picture, and types of response to thyroid therapy}

In this paper are presented 9 cases of permanent myxedema following treatment for toxic goiter. ${ }^{5}$ Table 1 gives skeleton outlines of the clinical and basal metabolic histories on the four cases not charted in the text.

The term "permanent" necessarily must be used in a relative sense; for even in instances where, on omission of thyroid extract, or its decrease below the maintenance dose, the myxedema has been shown to persist a year or more after its onset, e.g., case 1 (fig. 1), case 4 (fig. 4) and cases $6,7,8$ and 9 (table 1), there is no guarantee that it may

- One case (case 3) occurred after treatment in another clinic, thus explaining why it is not included in the figures for the incidence following treatment in this clinic. The clinical history of this patient when he was thyrotoxic has been reported by Means, J. H., and Richardson, E. P., The Diagnosis and Treatment of Diseases of the Thyroid, Oxford University Press (In press). Lab. No. 3947, Chapter 5.

Early data on 4 cases have been reported as follows:

Means, J. H., and Aub, J. C., The Basal Metabolism in Exophthalmic Goiter, Arch. Int. Med., 1919, xxiv, 645: Lab. No. 66 (case 4 in this paper) Lab. No. 33 (case 6) and Lab. No. 40 (case 8).

Means, J. H., and Holmes, G. W., (8): Lab. No. 66 (case 4), Lab. No. 628 (case 5).

Holmes, G. W., (13): Lab. No. 628, (case 5) (X-ray No. 3933).

Means, J. H., Hyperthyroidism-Toxic Goiter, Med. Clin. of North America, 1920, iii, 1077: Lab. No. 33 (case 6).

Practically complete data on 2 cases have been reported as follows:

Means, J. H., and Holmes, G. W., ibid., Lab. No. 33 (case 6).

Means, J. H., and Richardson, E. P., ibid., Fig. 37, Lab. No. 4103 (case 9). 


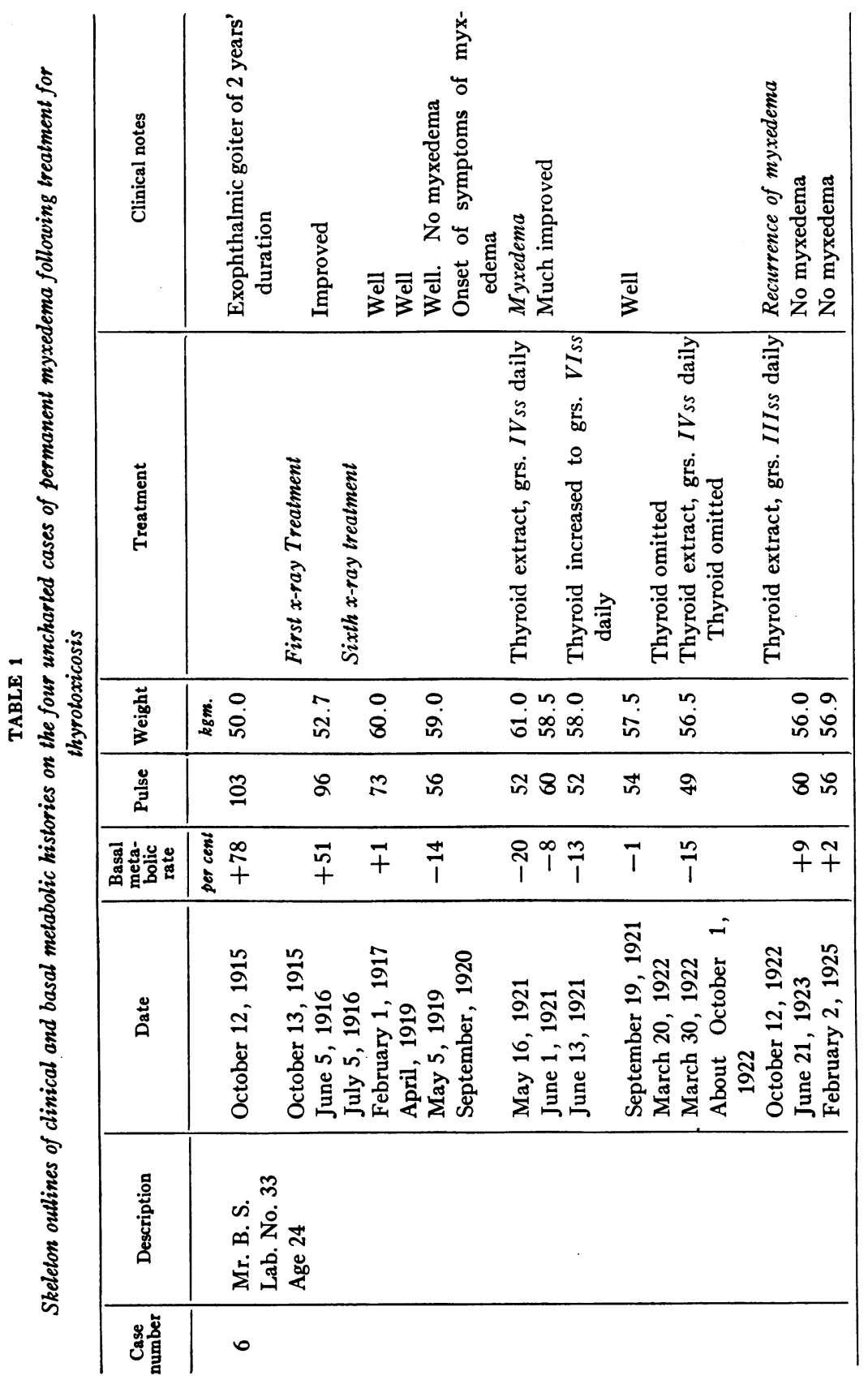


WILLARD OWEN THOMPSON AND PHEBE K. THOMPSON

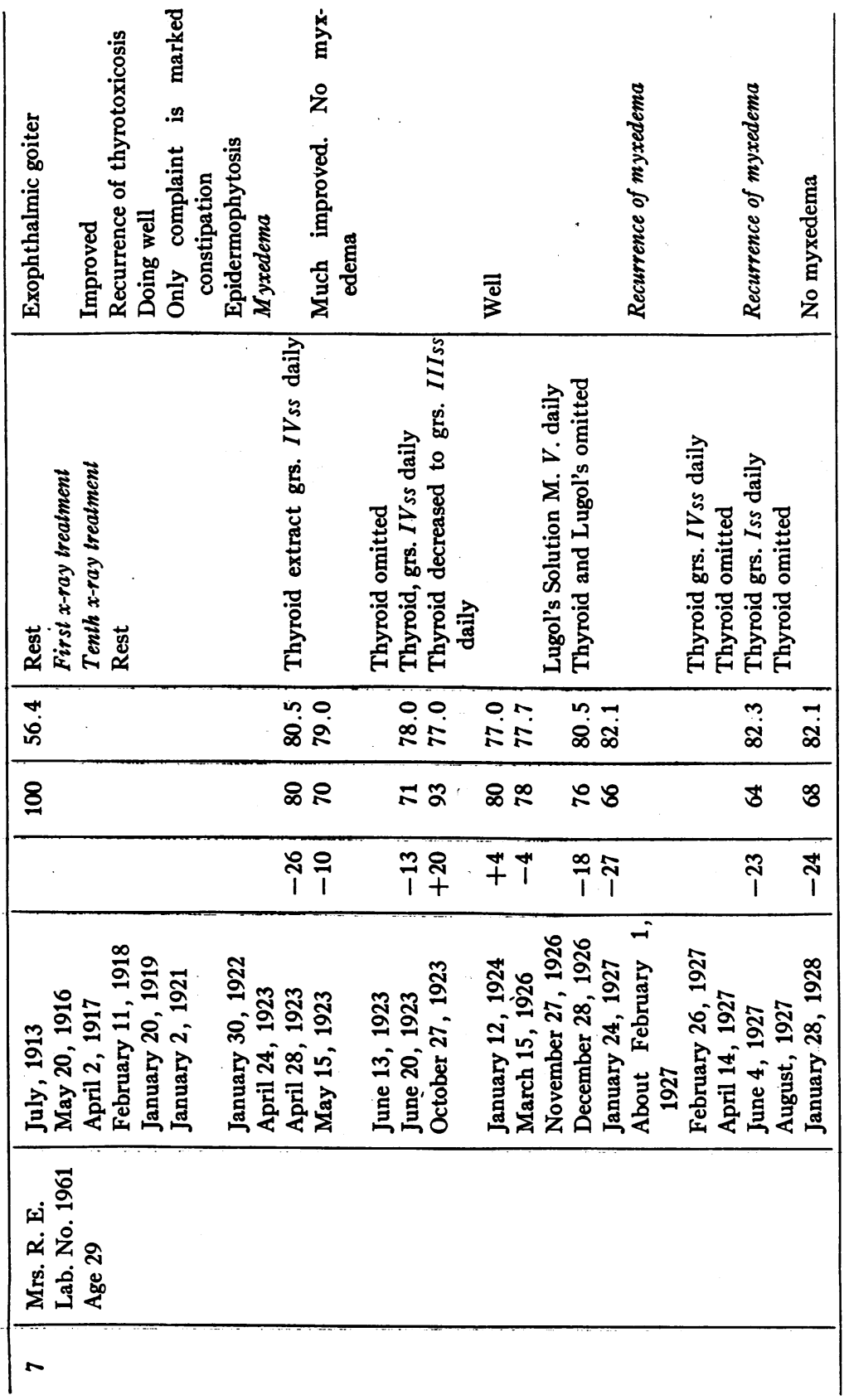




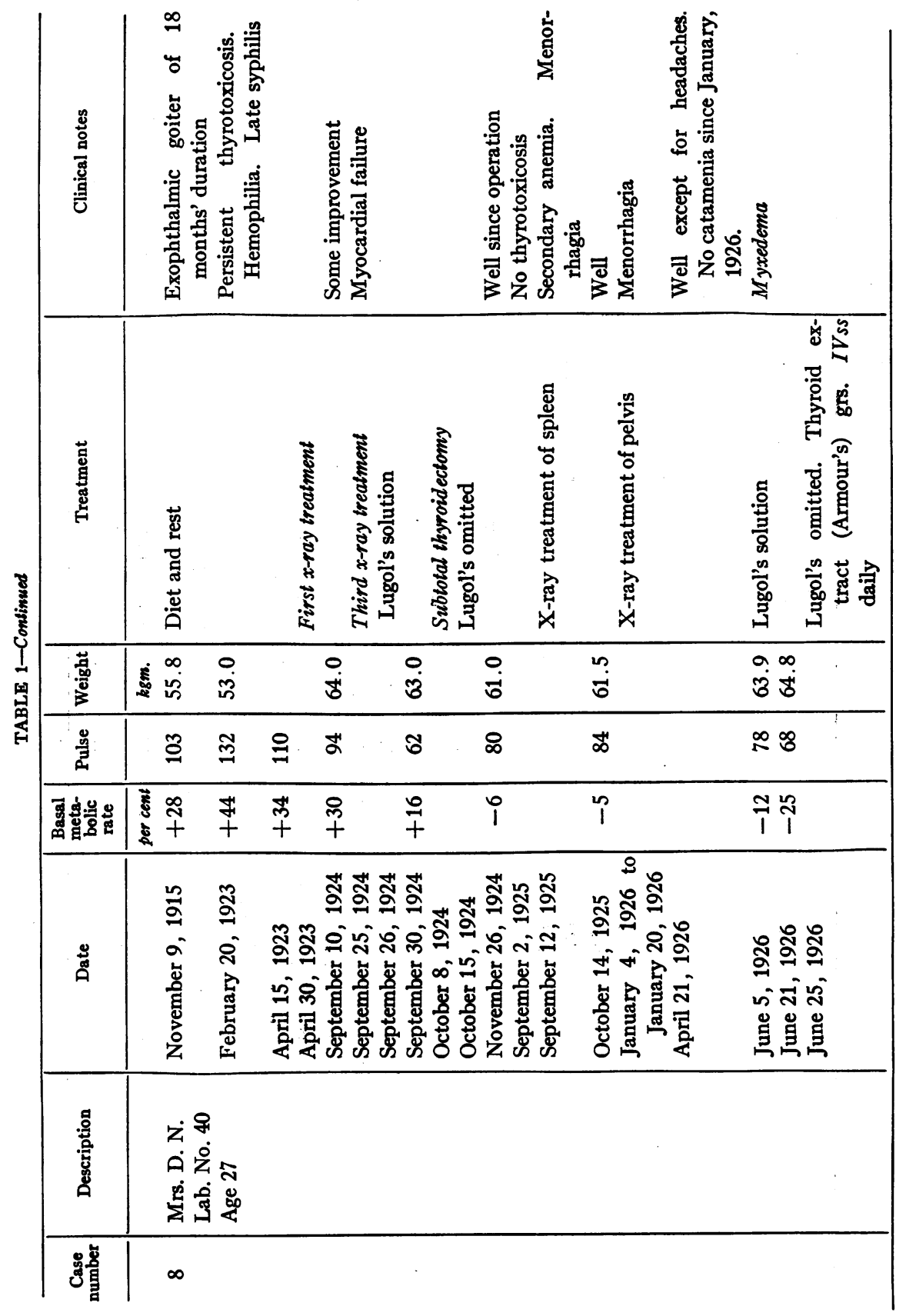


WILLARD OWEN THOMPSON AND PHEBE K. THOMPSON

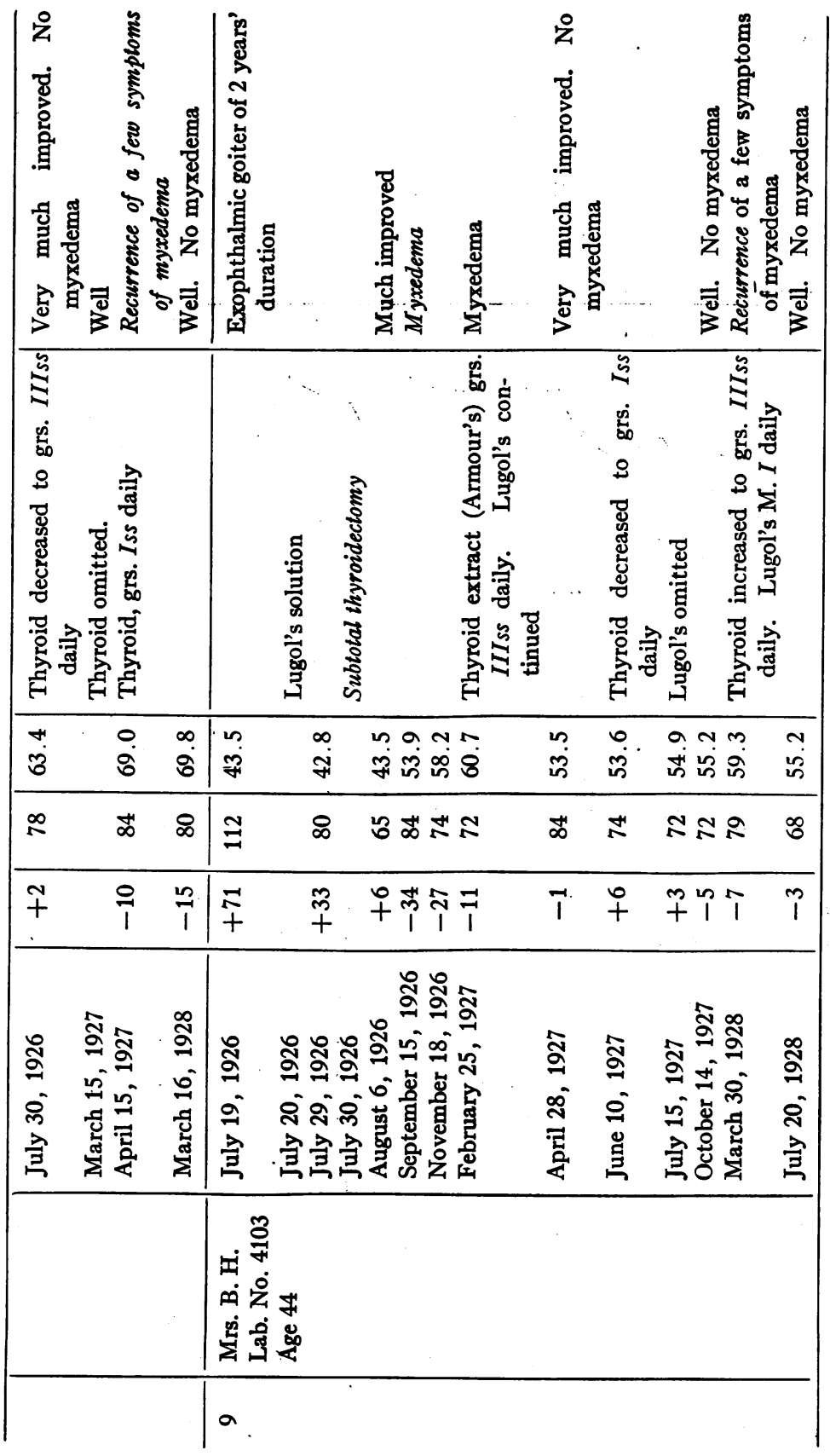


not disappear eventually as it did in case 11 (fig. 6). Moreover, 3 of the cases have never been tested by omission of thyroid therapy for a length of time sufficient to ascertain whether or not the myxedema would recur.

The diagnosis of myxedema was definite in all the cases except no. 8 (table 1). She had no noticeable edema, but her subjective symptoms

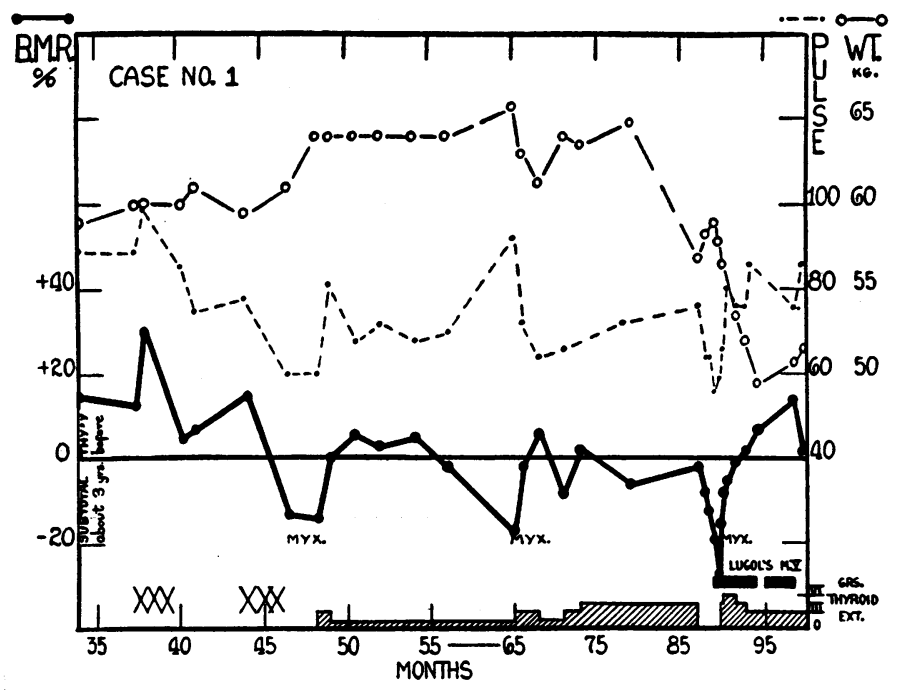

Fig. 1. Lab. No. 1505. Miss F. F. T. Age 47. Permanent Myxedema Occurring within 3 Months after X-Ray Therapy $(X)$ Preceded by Subtotal Thyromectomy (about 3 Years before First Metabolism Determination) for Exophthalmic GoIter

Marked exophthalmos persists to date. Maintenance dose of thyroid extract is 3 grains daily. In this and subsequent charts, black areas denote Lugol's medication, and cross-hatched areas, thyroid medication.

were characteristic and disappeared on thyroid therapy. Case 2 (fig. 2) ${ }^{6}$ is typical of the group, and, when myxedematous, presented the following signs and symptoms:

She was dopey, lacked energy, had a poor appetite, fatigued very easily and felt cold all the time. She had dyspnea on exertion. Her speech was slow and thick

- We wish to thank Dr. E. P. Richardson for the use of the data on this case. 
and her memory was poor. Her face was expressionless and her eyelids puffy. Her skin was rough and dry all over her body and her hair was dry and coarse. Her thyroid was just palpable, firm and irregular, the right lobe being larger than the left; whereas, when she had thyrotoxicosis, her thyroid was described as a "large, firm, vascular goiter, with a loud bruit and thrill."

On thyroid extract, she improved markedly. Her old hair gradually fell out as new hair grew in. Her skin peeled and became soft and smooth. There was much less dyspnea on exertion. The puffiness of her face disappeared and her expression became much brighter. She talked more quickly, was stronger, alert and energetic.

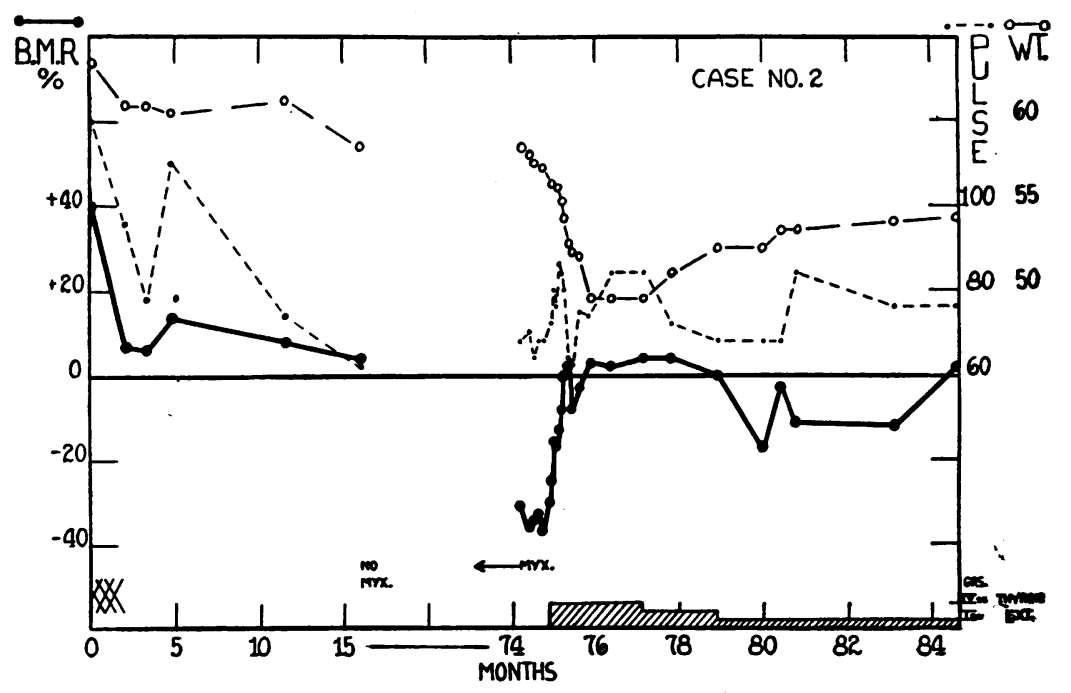

Fig. 2. Lab. No. 798. Miss A. K. R. Age 17. Onset of Myxedema about 5 Years afTer X-RAy Therapy $(X)$ FOR EXophthalmic GoITer

Maintenance dose of thyroid extract is $1 \frac{1}{2}$ to 3 grains daily

In his reaction to thyroid therapy case 3 (fig. 3 ) presents an interesting contrast to cases 2 (fig. 2), 5 (fig. 5), 1 (fig. 1) and 4 (fig. 4). The latter group show the typical response in myxedema, where $1 \frac{1}{2}$ to 3 grains of thyroid extract (Armour's) daily is usually sufficient to hold the basal metabolic rate at standard normal. In case 3 (fig. 3), however, the metabolism tended to remain at a low level, even when the patient received 6 grains of thyroid extract (Burroughs Wellcome) daily and was clinically well. When his rate was raised to minus 2 


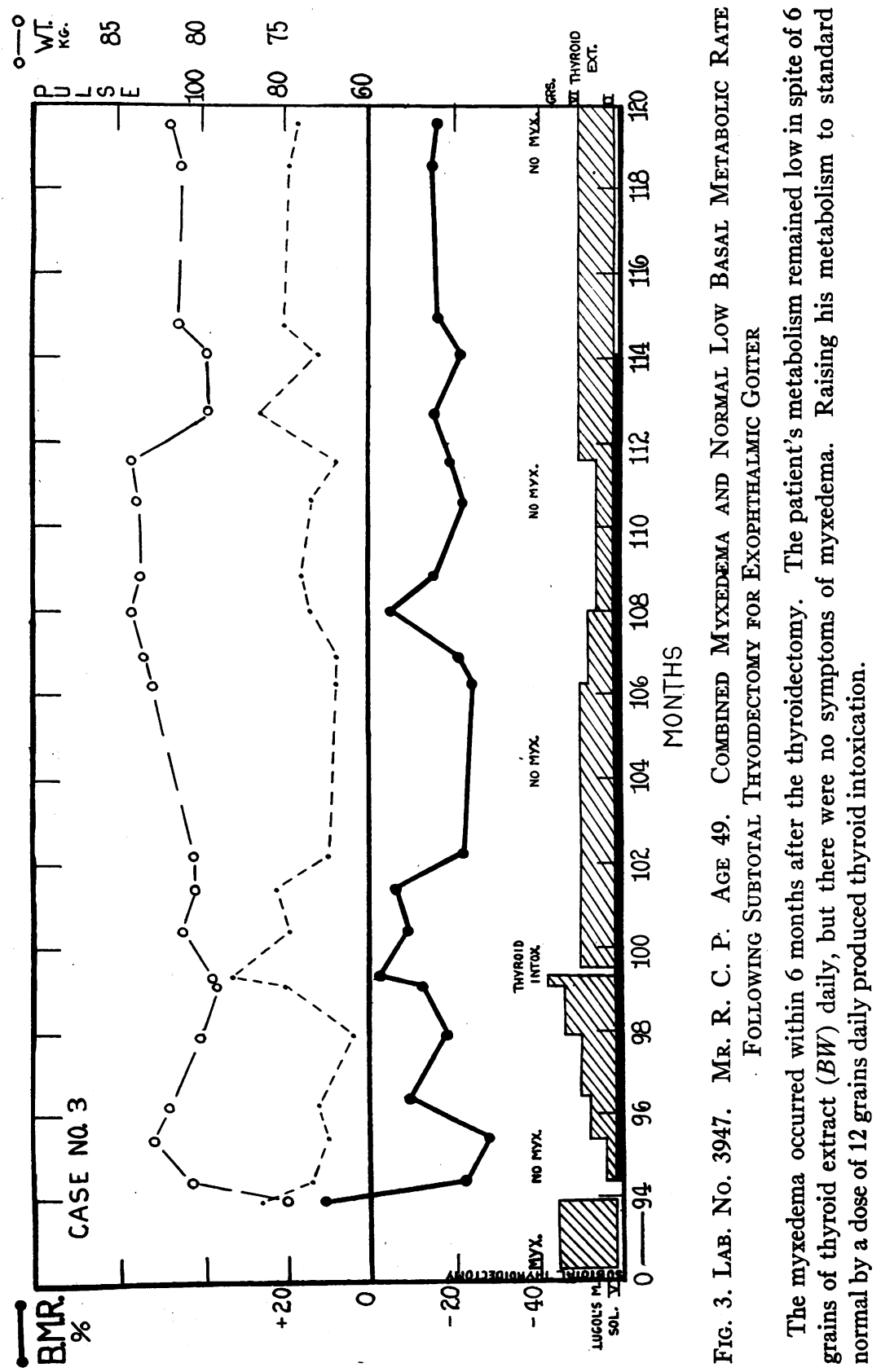


per cent by a dose of 12 grains daily, he developed thyroid intoxication, i.e., he suffered from palpitation, dyspnea and precordial pain. These symptoms disappeared promptly when thyroid was omitted. We have shown (7) that the majority of our patients with permanent low metabolism following thyrotoxicosis did not have myxedema and for the most part appeared to be normal individuals, i.e., their low metabolism was apparently a normal one for them. Like normal

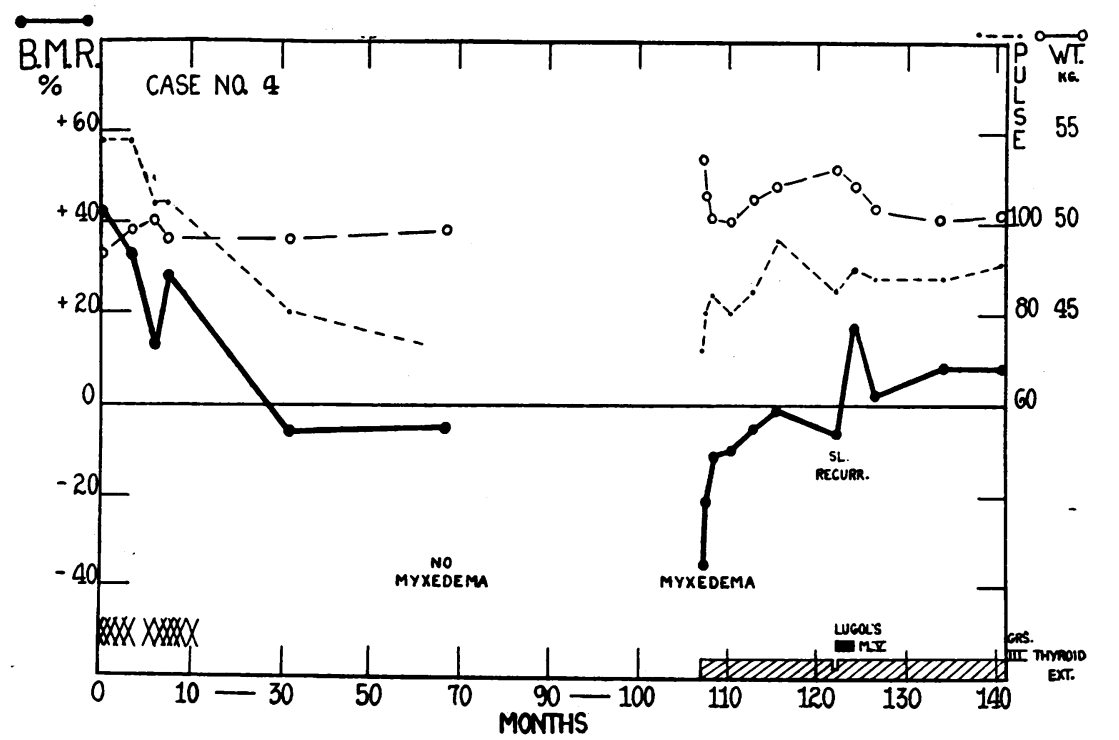

Fig. 4. Lab. No. 66. Miss E. C. C. Age 27. OnSet of Myxedema 5 to 8 YeARS AFTER X-RAY THERAPY $(X)$ FOR EXophthalmic GoITER

Maintenance dose of thyroid extract is $\mathbf{3}$ grains daily

individuals with a standard metabolism of plus to minus 10 per cent, some of these patients required much larger doses of thyroid extract than those required by cases of myxedema, in order to raise the metabolic rate appreciably. One such patient developed thyroid intoxication on 6 grains of thyroid extract; while her metabolism was still low. Judging from his response to thyroid therapy, it is probable that patient no. 3 has a low metabolism normally, regardless of whether or not he still has myxedema. 


\section{Late onset after $x$-ray therapy}

One of the most striking features brought out by a study of these cases was the late onset of the myxedema after $x$-ray therapy for thyrotoxicosis. This has been previously noted by Means and Holmes

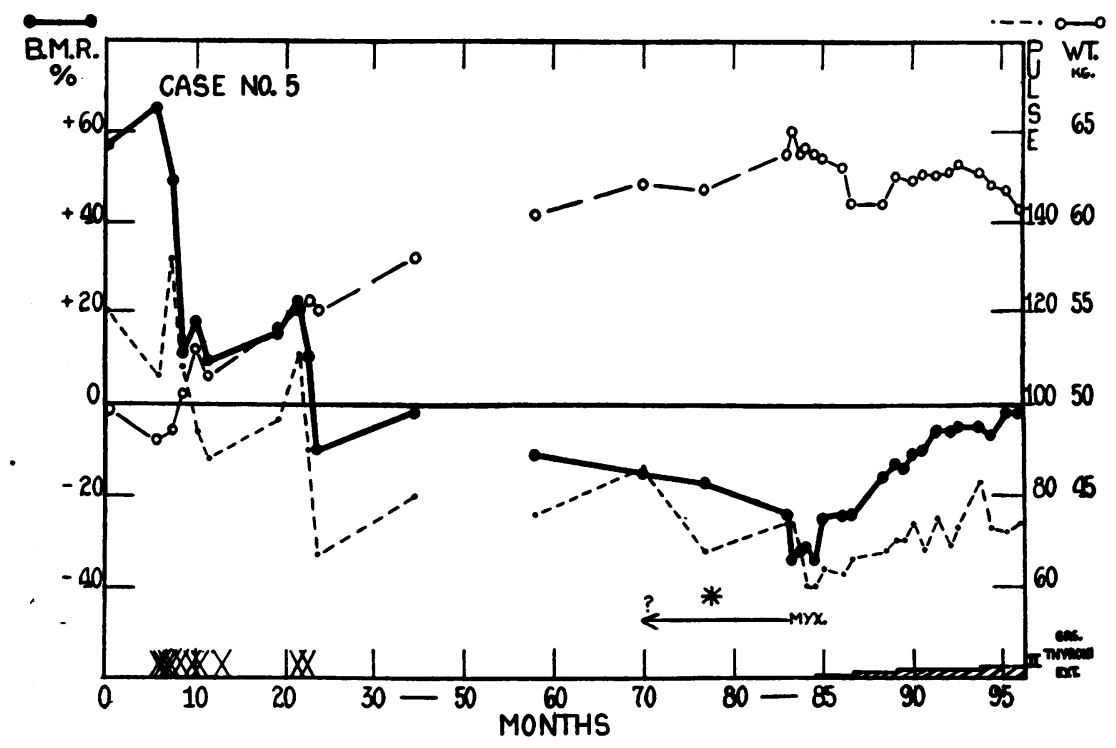

Fig. 5. Lab. No. 628. Mrs. M. J. Age 41. Onset of Myxedema 3 to 5 Years AFTER X-RAY Therapy $(X)$ FOR TOXIC GoITER

Symptoms noted shortly before radiation and removal of left breast for carcinoma $\left({ }^{*}\right)$. The patient is well and has a standard normal metabolic rate on $1 \frac{1}{2}$ grains of thyroid extract daily.

(8) in two patients. In the 5 cases thus treated, the times of onset were as follows:

Case
2 (fig. 2)
4 (fig. 4)
5 (fig. 5)
6 (table 1)
7 (table 1)

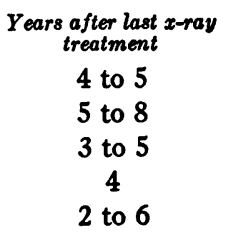

(In this connection, it is of interest that the onset of myxedema in the case of temporary myxedema following x-ray therapy was also late, 
viz., 1 to $1 \frac{1}{2}$ years after treatment.) The cases treated by surgery, or by surgery combined with $\mathrm{x}$-ray do not show this. In case 9 (table 1 ) and case 3 (fig. 3), treated by subtotal thyroidectomy alone, and in case 1 (fig. 1) treated by this form of therapy followed by $x$-ray, the onset of the myxedema was within 3 months after treatment. In case 8 (table 1) the myxedema appeared to be due as much to artificial inactivation of the gonads 6 months previously as to the subtotal thyroidectomy performed nearly 2 years before.

\section{PERMANENT MYXEDEMA FOLLOWING UNTREATED THYROTOXICOSIS}

The Report on Myxoedema published in 1888 (1), states "In a few cases the appearance of the symptoms of myxoedema has been preceded by exophthalmic goitre. It is not too much to say that in this aspect all cases of exophthalmic goitre ought to be followed with more care." Cases of this nature have been reported at infrequent intervals in the subsequent literature.

While probably a rare phenomenon in any case, it is particularly rare at present, due to the fact that nearly all patients with toxic goiter receive some form of treatment. For this reason the following case-as far as is known, the only one on record in this clinic-merits special consideration:

Case 10.7 Mrs. J. W. Lab. No. 4224. In September, 1899, when 23 years old, she was in this hospital for repair of a femoral hernia. At that time it was noted that she had a goiter, exophthalmos and a marked tremor. Her appetite was ravenous and she was very nervous. She had palpitation and tachycardia, her pulse rate averaging about 120 while in the hospital. A diagnosis of exophthalmic goiter was made. Her symptoms improved with rest in bed, and she was given no other treatment.

In 1907, in another city, she had "pneumococcal meningitis." Shortly afterwards she developed swelling of the hands, face and feet, and was described as having a "cow-like" expression. Her tongue became dry, her hair dry and thin, and her nails hard. She was irritable, lacked ambition, and displayed no interest in her family or surroundings. Her appetite was poor and she was always drowsy. The diagnosis of myxedema was made. She was given thyroid extract, which produced marked improvement.

7 The observations on the protein content of the cerebro-spinal fluid and on the basal metabolic rate on this patient are published elsewhere (9) (17). 
When next seen in this hospital in June, 1909, she was taking thyroid, but irregularly. Her goiter and exophthalmos had disappeared. She had no edema, her speech was normal and her facial expression "only suggestive, but not characteristic of myxedema." Her tongue was large, her hair and skin were dry and she felt chilly. She began taking thyroid regularly and felt better. In December, 1910, it was regulated at 5 grains (Burroughs Wellcome) daily.

In the next nine years, she underwent four operations in other hospitals, two for removal of Fallopian tubes, ovaries and uterus on account of menorrhagia, and two for herniae in the scars. During this time, whenever thyroid extract was omitted she became myxedematous again. In January, 1920, at the time of her last operation, a high blood pressure was noted. Her dose of thyroid varied from 2 to 4 grains daily for some time thereafter. In April, 1926, she was in another hospital because of a recurrence of her myxedema. She had her first basal metabolism determination, which was minus 28 per cent. She was discharged improved on 3 grains of thyroid extract daily.

In September, 1926, she returned to this hospital because of failing vision. She stated that she was taking 8 grains of thyroid (unknown brand) daily, but this was doubtful in view of her symptoms. She looked myxedematous. Her face was puffy. She was lethargic and always tired and sleepy. Her voice was hoarse, her tongue large, her hair coarse and her skin dry. Her heart was enlarged and her blood vessels somewhat sclerosed. Her blood pressure was $\frac{238}{130}$. Her basal metabolism was plus 3 per cent and her pulse rate 80 . Thyroid was omitted until December 1926, during which time her metabolism fell to minus 20 per cent, and her signs and symptoms became so pronounced that there was no doubt about the diagnosis of myxedema. She had the high protein concentration in her spinal fluid and the albuminuria so often present in this disease (9). She improved on gradually increasing doses of Armour's thyroid extract. The albuminuria disappeared and the protein content of the spinal fluid decreased markedly on this medication (9). Four grains daily, however, produced symptoms of thyroid intoxication, viz., nausea, vomiting, precordial and epigastric pain and palpitation. These disappeared when thyroid was omitted for a short time. A dose of 2 grains daily was resumed. This dose proved satisfactory, and maintained her metabolism at a normal level for several months. There were no signs nor symptoms of myxedema, and she felt as well as could be expected in view of her hypertension. After a time, however, she developed marked precordial pain and palpitation with a basal metabolic rate of plus 26 per cent. It was again necessary to stop the administration of thyroid extract. Her myxedema recurred. After an interval of 5 months, 3 grains of Armour's thyroid daily was started, but in a few days caused a recurrence of her precordial pain. The dose was finally regulated at $\frac{1}{2}$ grain of Armour's thyroid daily. This has maintained the basal metabolic rate at a normal level. has caused no precordial pain, and her myxedema has not recurred. 


\section{TEMPORARY MYXEDEMA FOLLOWING TREATED THYROTOXICOSIS}

The Report on Myxoedema (1) states that there was "a tendency to improvement or even to complete disappearance of the cachexia in a certain, number of cases of operative myxoedema." Since then, the published observations on this phenomenon have been very few. A case was reported by Setti (10) in 1907. In 1921 a case (Lab. No. 485) following x-ray treatment at the Massachusetts General Hospital was reported (11), (12), (13). Means and Holmes in 1922 (14) and in 1923 (8) reported this case and an additional one (Lab. No. 575). Pfahler (15) in 1926 is quoted as having observed such a case.

The cases of temporary myxedema presented here are two on record in this clinic, in which the diagnosis appeared to be definite.

If all our cases of temporary low metabolism following treated thyrotoxicosis were counted as temporary myxedema, the latter would be a fairly common occurrence (about 12 per cent of the cases). We have previously reported (16), however, that about 85 per cent of the patients with temporary low metabolism showed no clinical evidence of myxedema. Although some of these low rates without myxedema seemed to be a transient return to the patient's normal low metabolic level, there were a certain number which could be explained best by the hypothesis of a temporary hypothyroidism, not detectable clinically. This, however, is not sufficient justification for including them in a study of temporary myxedema. Then again, there are several cases which, following treatment for toxic goiter, show, temporarily, signs and symptoms which strongly suggest myxedema, the outstanding feature being a puffy face (6), but due to the fact that such a diagnosis is somewhat open to question, they also are not included here. $^{8}$ On account of these uncertainties of diagnosis, it is impossible to give any estimate of the incidence of temporary myxedema following treated thyrotoxicosis, in this clinic.

Outlines of the clinical histories, and charts showing the course of the

${ }^{8}$ In our papers on temporary and permanent low metabolism without myxedema (16) (7), fifteen per cent of each group were cited as having had temporary myxedema. Later, with a low metabolism, these patients were symptom free. Further observation of similar clinical pictures has led us to question the diagnosis of myxedema in several instances. Until more light is thrown upon the subject, we prefer to call the syndrome a temporary post-operative edema. 
basal metabolism in the two cases in which the diagnosis of myxedema appeared to be definite, are given below:

Case 11 (fig. 6). Lab. No. $348 .^{9}$ Mrs. M. B. Age 38. In September, 1920, 8 months after $6 \mathrm{x}$-ray treatments (ending in January, 1920) for toxic gaiter, she was clinically well and had a basal metabolism of minus 3 per cent. In February, 1921, her metabolism was still normal, and the only symptom present was numbness of the hands. She looked somewhat pale and her skin was a little dry. In

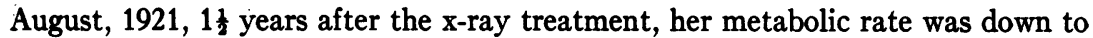
minus 35 per cent. There had been a weight gain of $9 \mathrm{kgm}$. since 1920 . She had not been well for 3 months. She complained of numbness of her hands, general weakness, pains in her legs on climbing stairs, and marked constipation. She felt cold and did not perspire during the hot days. She appeared dull. Her face was expressionless, her speech slow and her skin dry and coarse. Her lips were bluish and her face and conjunctivae pale. A diagnosis of myxedema was made.

Thyroid extract was started. This produced marked improvement and raised her metabolism to standard normal by September, 1921. On two subsequent occasions, one in June, 1922, and one in August, 1922, when she omitted thyroid for 3 weeks, her rate fell to minus 23 per cent each time, and she became tired and slowed up. Her skin became dry and her face expressionless again. She resumed thyroid and felt perfectly well. On November 9, 1926, at which time her metabolism was minus 11 per cent, thyroid was omitted. Her metabolic rate gradually fell, until by March, 1927, it was minus 23 per cent. Until June, 1928, a period of $1 \frac{1}{2}$ years from the time thyroid was omitted, it ranged from minus 8 to minus 22 per cent, with one observation of zero. There was no return of symptoms of myxedema. Her hair and skin did not become drier. There was no evidence of edema and no decrease in strength and energy. She was not slowed up, never felt like sleeping in the daytime, and could do all her own housework without fatigue, rising at $6 \mathrm{a} . \mathrm{m}$ and retiring at 9 to $10 \mathrm{p} . \mathrm{m}$. She looked well and insisted that she felt just as well, if not better, than when taking thyroid extract.

Case 12 (fig. 7). Lab. No. 2940.10 Mrs. E. B. C. Age 48. This patient had a subtotal thyroidectomy for exophthalmic goiter on December 10, 1924. Up to March, 1925, her basal metabolism ranged from minus 10 to minus 16 per cent and she was exceptionally well. By May, 1925, her metabolic rate was minus 25 per cent. Her memory was failing and she was becoming weak and lethargic. Her

- Earlier data on this case have been reported before as follows:

Holmes, G. W., (13) (X-ray No. 3740).

Means, J. H., and Holmes, G. W., (8).

More complete data have been reported by:

Thompson, W. O., and Thompson, P. K., (7).

10. We wish to thank Dr. J. H. Means for the use of the data on this case, which has been reported before by Thompson, W. O. and Thompson, P. K., (7). 
WILLARD OWEN THOMPSON AND PHEBE K. THOMPSON 363

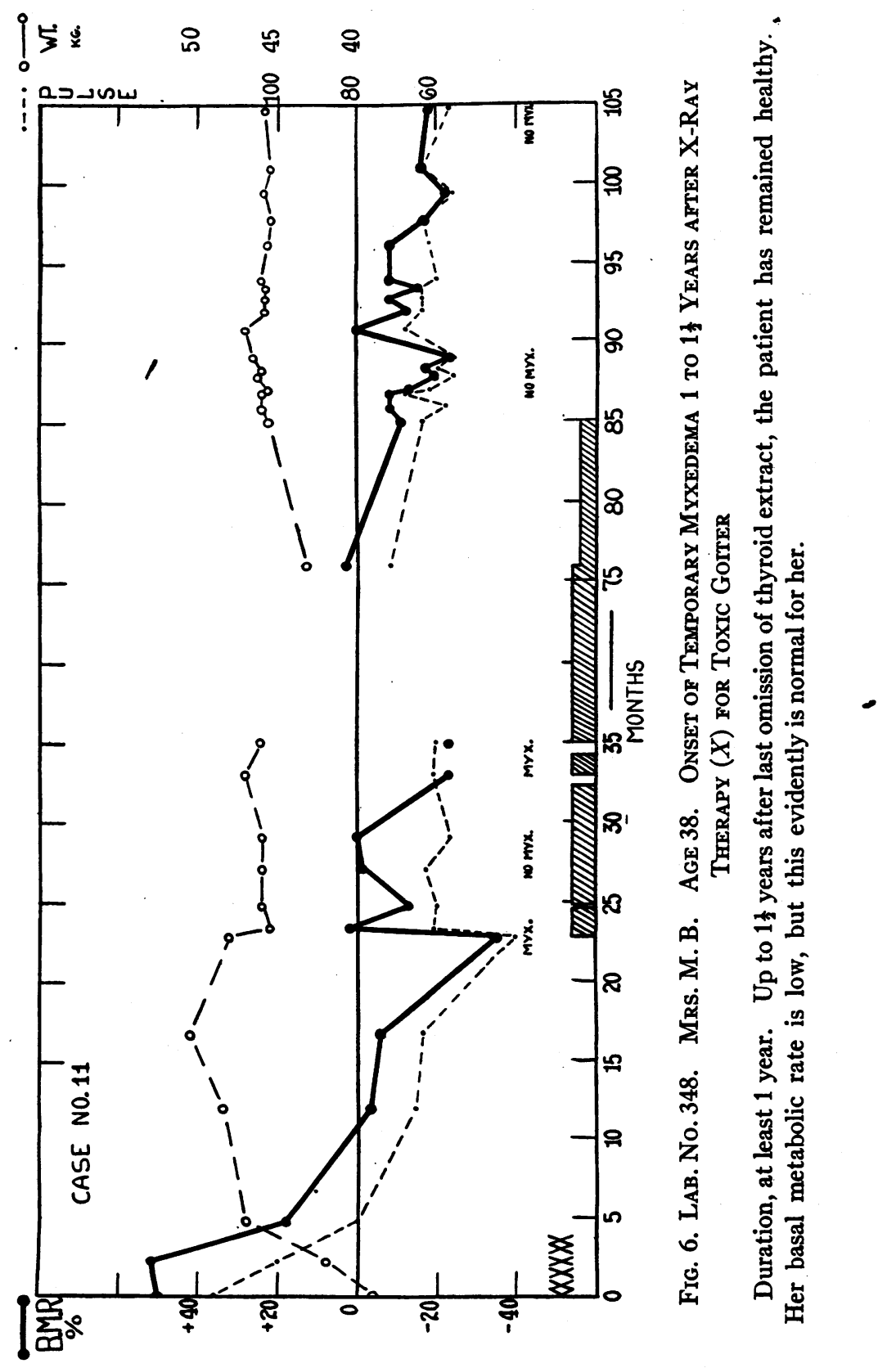


hair was falling out and her voice was becoming husky. A diagnosis of myxedema was made. Thyroid extract (Burroughs Wellcome), $1 \frac{1}{2}$ grains daily, was started and gradually increased to 4 grains daily. While on this medication, her metabolism did not rise above minus 7 per cent, and usually ranged in the vicinity of minus 15 per cent. She felt well and had no symptoms of myxedema. In January, 1927 , nearly 2 years after starting it, thyroid was omitted. From then until May, 1927, her metabolism ranged from minus 17 to minus 28 per cent, and she felt as well as ever, except for some fatigue attributed to unusually heavy work that she

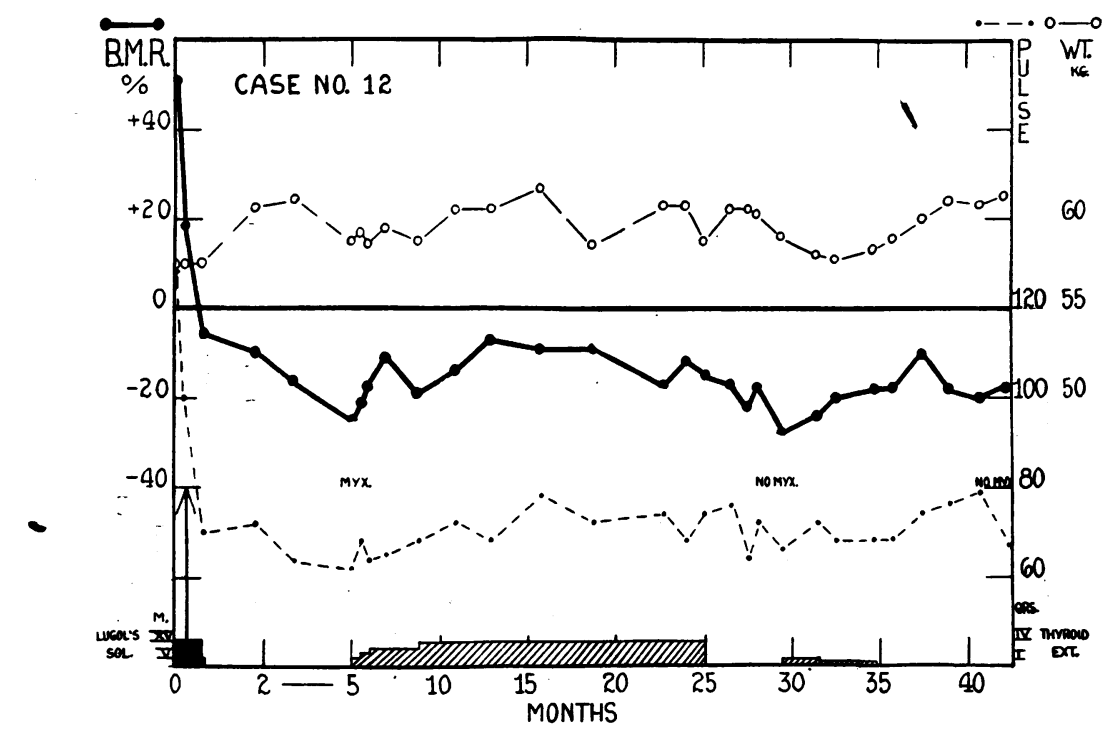

Fig. 7. Lab. No. 2940. Mrs. E. B. C. Age 47. Onset of Temporary MyxeDEMa 4 to 5 Months after SUbtotal Thyromectomy (ARROW) For EXOPHTHALMTC GOITER

For 4 months after first omission, and $7 \frac{1}{2}$ months after last omission of thyroid extract, the patient has remained healthy. Her basal metabolic rate is low, but apparently this is normal for her.

had undertaken at the time of omission of thyroid. Thyroid in small doses was given again, without any clinical or metabolic effect. In October, 1927, it was omitted for a second time. Up to June, 1928, her metabolic rate was still low (minus 18 per cent) and she had experienced no clinical change. She had plenty of drive and energy, and was bright and alert. She was able to take full care of an 8-room house, run a chicken farm, and do a great deal of church and club work, including lecture tours, without undue fatigue: in fact, she could outdo her friends. There was no evidence of myxedema. 
Case 11 (fig. 6) showed a practically typical picture of myxedema. In case 12 (fig. 7) it was much less definite, yet after careful questioning of the patient about her condition in May, 1925, as compared with the present time, the diagnosis of myxedema seemed justified.

In each instance the myxedema was only temporary. The patients remained healthy individuals long after thyroid therapy was discontinued.

The late onset of the myxedema in case 11 is of interest, particularly in connection with the late onsets in most of the cases of permanent myxedema following $x$-ray treatment.

In case 12 , the duration of the myxedema is unknown, as thyroid therapy was continued for nearly 2 years uninterruptedly: but in case 11 it was at least 1 year, evidenced by the fact that up to that time, the myxedema promptly returned whenever thyroid extract was omitted.

\section{DISCUSSION}

The small amount of normal thyroid tissue necessary to furnish the body with a sufficient amount of thyroid hormone is remarkable, as is well known from experimental observations on animals. The rarity of permanent myxedema following subtotal thyroidectomy for toxic goiter in man, indicates that one-sixth to one-eighth of a diseased gland is, in most instances, capable of supplying body needs. Moreover, in the days when thyroidectomies were complete, the very small remnants or else accessory thyroids which were evidently overlooked, prevented myxedema in two-thirds of the cases (1).

In a discussion of the effect of any form of treatment for thyrotoxicosis upon the incidence of myxedema, it is necessary to know the incidence of the latter following the untreated disease. As far as is known, no series of untreated cases of thyrotoxicosis has been followed long enough and in sufficient numbers to ascertain this. At present, when nearly all cases receive some form of treatment, such information is very difficult to obtain.

The onset of myxedema so long after x-ray therapy in our series, raises the question of whether the $\mathrm{x}$-ray was the causative factor, inasmuch as myxedema may occur spontaneously in cases of thyrotoxicosis which have never had any treatment. In this clinic, the incidence of myxedema following untreated toxic goiter probably would not exceed 
that of myxedema following subtotal thyroidectomy, i.e., about 1 per cent: whereas, after $\mathrm{x}$-ray, the incidence was about 4 per cent. This suggests that $\mathrm{x}$-ray had a definite influence in causing the myxedema in our series. The number of cases on which these figures are based however, is necessarily so small that one cannot place much reliance upon such apparent differences in incidence. In any event, the incidence of myxedema following $\mathrm{x}$-ray therapy of the thyroid is not great enough to constitute a contraindication to this form of treatment.

If the myxedema be an x-ray effect, it is similar in its late onset to such other $\mathrm{x}$-ray effects as skin atrophy and telangiectasis, and is probably due to a very slow fibrosis of the thyroid gland tissue. Skin and gland changes do not go hand in hand however. In only one case of this series was there any evidence of skin changes. Case 4, treated in the year 1916 before the technique was perfected, shows a small amount of telangiectasis. Thus, if the myxedema be due to $x$-ray therapy, sufficient dosage to destroy thyroid tissue in $\mathbf{5}$ cases, affected the skin over the gland in only one case. On the other hand, we have a patient first treated in the year 1915 who now shows considerable telangiectasis, but who still has thyrotoxicosis. If the change produced in the gland is in the nature of a gradual fibrosis, it evidently does not preclude a restoration of gland function at a later date, as shown by case 11 (fig. 6), where myxedema occurred over a year after x-ray treatment and persisted for at least 1 year, but did not recur up to $1 \frac{1}{2}$ years after omission of thyroid extract. Another $x$-ray effect which might be considered comparable to this is that of restoration of function of the ovaries after it has been suspended by x-ray treatment. Here, however, the onset of the ovarian deficiency is immediate, and not delayed, as may be the onset of thyroid deficiency.

The fact that the myxedema may be temporary has an important bearing upon thyroid therapy. It shows the desirability of periodic omissions of this medication in order to prevent unnecessary administration, in a certain number of cases.

SUMMARY AND CONCLUSIONS

1. Myxedema following treatment for thyrotoxicosis may be either temporary or permanent. 
2. The latter is a rare occurrence. Its incidence in this clinic has been less than 1 per cent following subtotal thyroidectomy and about 4 per cent following $x$-ray therapy.

3. It may occur following untreated toxic goiter.

4. A striking feature of most of the cases in which the thyrotoxicosis was treated by $x$-ray, was the late onset of the myxedema-up to 5 years after treatment. A myxedema of temporary duration may begin as late as 1 to $1 \frac{1}{2}$ years after the completion of such treatment.

5. Thyroid therapy should be omitted periodically in order to judge whether the myxedema be temporary or permanent.

\section{BIBLIOGRAPHY}

1. Report on Myxoedema. Supplement to Vol. xxi of Clin. Society's Trans. London 1888. Pages 168-171.

2. Judd, E. S., Collected Papers of the Mayo Clinic, 1916, viii, 544. Surgery of the Thyroid.

3. Jordan, S. M., Arch. Surg., 1925, xi, 1. Basal Metabolic Rates and Their Relation to End-results in Thyroid Disease.

4. Smith, L. W., Clute, H. M., and Strieder, J. W., Surg. Gynec. Obst., 1928, xlvi, 325. The Results in One Hundred Consecutive Cases of Hyperthyroidism Operated Upon.

5. Elliott, C. A., Trans. Assoc. Am. Phys., 1926, xli, 93. Results of Thyroidectomy for Hyperthyroidism as Indicated by Examination a Year or More Following Operation.

6. Thompson, W. O., and Thompson, P. K., Unpublished data.

7. Thompson, W. O., and Thompson, P. K., J. Clin. Invest., 1928, v, 471. Low Basal Metabolism Following Thyrotoxicosis. II. Permanent Type Without Myxedema.

8. Means, J. H., and Holmes, G. W., Arch. Int. Med., 1923, xxxi, 303. Further Observations on the Roentgen-Ray Treatment of Toxic Goiter.

9. Thompson, W. O., Thompson, P. K., Silveus, E., and Dailey, M. E., J. Clin. Invest., 1928, vi, 251. The Protein Content of the Cerebro-spinal Fluid in Myxedema.

10. Setti, G., Riv. veneta di Sc. med., 1903, xxxviii, 433. Di una sindrome di mixoedema post-operatorio guarito spontaneamente.

11. Means, J. H., J. Am. Med. Assoc., 1921, lxxvii, 350. Determination of the Basal Metabolism.

12. Seymour, M., Boston Med. Surg. J., 1921, clxxxv, 261. 'Myxedema Following Treatment of Graves' Disease with Roentgen Ray.

13. Holmes, G. W., Am. J. Roentgenol., 1921, viii, 730. Some Observations on the Treatment of Hyperthyroidism with X-Rays. 
14. Means, J. H., and Holmes, G. W., Trans. Assoc. Am. Phys., 1922, xxxvii, 198. Further Observations on the Roentgen-Ray Treatment of Toxic Goiter.

15. Pfahler, G. E., Quoted by Stevens, J. T. in discussion of "Hyperthyroidism" by Barclay, A. E. Radiology, 1926, vi, 21.

16. Thompson, W. O., and Thompson, P. K., J. Clin. Invest., 1928, v, 441. Low Basal Metabolism Following Thyrotoxicosis I. Temporary Type without Myxedema, with Special Reference to the Rôle of Iodine Therapy.

17. Thompson, W. O., Thompson, P. K., Silveus, E., and Dailey, M. E., Arch. Neur. and Psychiatry, In press. The Cerebro-spinal Fluid in Myxedema. 